\title{
Obstacles to Small Innovative Companies' Development: Case Study of Nizhny Novgorod Region
}

\author{
Nadezhda Butryumova ${ }^{1 *}$, Svetlana Karpycheva ${ }^{1}$, Khristina Grisheva ${ }^{1}$, Elena Kasyanova ${ }^{1}$
}

\begin{abstract}
The article presents the survey results of obstacles to small innovative companies as a case study of Nizhny Novgorod region of Russia as an area with high innovative potential and great level of socio-economic indicators. Based on the semi-structural personal interviews with 19 experts - the management of support infrastructure, results shows some typical for this region impediments: bureaucracy; lack of trust, poor collaboration within the innovation system; poor information support; legislative obstacles to innovations and intellectual property protection; low interest of large companies in collaboration with small ones. The findings and recommendations can help policy-makers to meet the needs of small innovative companies, and increase the innovative activity of small firms through the improvement of the assistance programs.
\end{abstract}

Keywords: small innovative companies; innovation infrastructure; obstacles; case study; Nizhny Novgorod region, Russia.

Submitted: April 30th 2015 / Approved: December 2nd 2015

\section{Introduction}

Different research shows that innovative ventures give more social and economic input than non-innovative, owing to the fast growth of small innovative companies, especially in the high tech industry (Geroski, 1995; Weigand \& Audretsch, 1999).

Small innovative companies face high risks and high costs when they launch innovative products and implement innovative processes. The effectiveness of the process of commercialization of innovations by SME is dependent on their collaboration with infrastructure and technology support network for innovation development (Zeleny, 2012). In order to increase the innovation activity and survival of SMEs at the regional level, it is necessary firstly to conduct a systematic analysis of the obstacles to their innovation activity that concern functioning of innovative infrastructure, and secondly, to improve rules and institutions to reduce the obstacles. It proves the relevance of the suggested research topic.

Good governance affects innovation across several dimensions. Government policy determines the regional infrastructure and significantly influences innovations (Sivak et al., 2011). Economic growth of the country depends on the economic growth of its regions that vary within the country (OECD, 2013). The right policy and coordination among different levels of administration can improve competitiveness of underperforming regions. Thus it is very important to investigate conditions for small innovative companies' development at a regional level. Such conditions depend on the innovation infrastructure of the region.

In accordance with the Federal Low on Science and State Science and Technology Policy 1996 innovation infrastructure of the region is represented by the organizations that enable and assist implementa- tion of innovative projects, including the provision of administrative, logistics, finance, information, personnel, and organizational consulting services. Innovative infrastructure can be divided into several types depending on the kind of support such organizations provide: financial, information, consulting and business service, personnel, industrial and technological infrastructure (Dezhina, 2005).

According to the Global Innovation Index report in 2013 Russia occupies the 51st place out of 141 in terms of innovation development ("The Global Innovation Index 2013. The Local Dynamics of Innovation," 2013). At the same time only 5.1\% of Russian small companies were engaged in technological innovation in 2011 (Ramos-Vielba \& Fernández-Esquinas). It shows the relevance of increasing the innovation activity in Russia and paying attention to the obstacles to innovations for SMEs.

Considering significance of SMEs for the economic development and importance of innovations, we need to identify issues and factors that negatively affect the development of small innovative businesses in the Russian regions with high innovative potential and great level of socio-economic indicators. Nizhny Novgorod region is a good case of such an example.

Choosing the Nizhny Novgorod region as the research object is justified by high levels of social, economic and innovative development in the region. The region took the fourth place in the ranking of innovative development in 2012 (Gokhberg, 2014). In the ranking of innovative activity of regions, Nizhny Novgorod was at the fourth place (Silvernagel et al.). However, we can see a low level of innovation activity of small business in this region. We can presume that there are significant barriers in the region to the development of small innovative companies.

1 Venture Management Department, National Research University Higher School of Economics.

Corresponding author: nbutrymova@hse.ru

ISSN: 0718-2724. (http://jotmi.org)

Journal of Technology Management \& Innovation ( ) Universidad Alberto Hurtado, Facultad de Economía y Negocios. 
The suggested article presents and analyses the results of the survey conducted in 2013 in order to solve that problem and find unique obstacles for such regions. Based on the semi-structural personal interviews with 19 experts representing the management of the organizations of innovation infrastructure, the issues typical for this region have been identified.

The findings could be helpful to the policy-makers in their attempt to meet the needs of small innovative companies and adjust the existing assistance programs. The suggested recommendations may help governments to increase the innovative activity of small firms in their regions. It could also help other countries to anticipate the same issues and adapt their policies to possible impediments that their SMEs may face.

This way, researchers can use the results of this investigation as hypothesis for their study, and verify the presence of such obstacles in the considered region.

The paper consists of several parts. The literature review introduces the general obstacles to innovations and the particular issues that small innovative companies may face. The next section presents the selected region and explains the methodology of the research. The "Results" section describes and analyses the identified barriers. The last section summarizes the research findings, compares the obtained results with Russian and foreign researchers, and provides directions for the future research.

\section{Obstacles to innovations faced by SMEs}

Impediments to innovation decrease the innovative activity of firms, and it is crucial to overcome them. A high risk and low level of survival of small innovative firms make it necessary to improve this activity by identifying and overcoming barriers and obstacles to innovation ventures. The issue of the barriers raises concern of a large number of scholars who discuss it from different points of view. Some authors consider barriers to innovations in general, other researchers study only obstacles to innovations for SMEs. The major part of the existing research seems to be focused on the general obstacles to innovations. Most of papers divide impediments into two categories: internal and external.

One of the first studies of this topic was conducted by Piatier in Europe. He identified barriers to innovation created by external and internal environment and ranged them into five enlarged groups that cover a wide spectrum of smaller ones: research and development (R\&D) policies; general, economic, and social policies; activity of the national private sector and universities; innovation climate; foreign countries. Policy, climate, legislation, and standards were included in the list of the strongest barriers (Piatier, 1984). Some researchers investigating barriers to innovations in different national and industrial contexts divide the identified barriers into the same categories: internal and external. But these obstacles are more specific than Piatier's ones.

In the other part of works the specific attention is paid to the obstacles to innovations faced by SMEs. A survey of high-tech enterprises conducted in China shows that the more innovative a company is, the more obstacles it meets, but some barriers do not depend on the innovation activity of the company (Huang \& Chi, 2013). For instance having assessed the impact of such barriers it was found out that the most critical impediments referred to the external factors and they could be divided into several groups: financial, personnel, services of support infrastructure, access to the information.

As a result of literature analysis we can find several impediments to innovations that are mentioned in the majority of studies. In this paper we study external obstacles for small innovative companies from the innovation infrastructure point of view.

The authors considered the emphasis on the lack of financial resources to be the strongest factor affecting the innovations in small firms. The research undertaken in Italy shows that the need of additional financing decreases the R\&D activity of Italian manufacturing SMEs (Mancusi \& Vezzulli, 2010). The results show that barriers concerning managers' perceptions of issues related to costs are stronger for small companies, and issues related to human resources are more important barriers to innovation for medium-sized firms (Madrid-Guijarro et al., 2009).

Such obstacle as lack of an appropriate source of finance for innovation companies was identified by several scholars and it means unfavorable bank credit policies, shortage of venture capital (Galia \& Legros, 2004; Hadjimanolis, 1999; Larsson, 2004; Madrid-Guijarro et al., 2009; Mohnen \& Roller, 2005). Barriers for SMEs related to finance in different papers concern such issues as: high cost of development; difficulties of costs control; lack of financial capital; difficult access to financial resources (Huang \& Chi, 2013; Madrid-Guijarro et al., 2009; Tourigny \& Le, 2004; Xie et al., 2010).

Labor-related problems were discussed by many researchers and they concern the shortage of skilled and qualified personnel (Arundel, 1997; Baldwin \& Lin, 2002; Galia \& Legros, 2004; Hadjimanolis, 1999; Larsson, 2004; Madrid-Guijarro et al., 2009; Mohnen \& Roller, 2005; Vrgovic et al., 2012). Personnel-related obstacles for SMEs are more specific than for large companies: inability to devote staff on an ongoing basis in the process of creating innovations due to production requirements; lack of skilled and qualified personnel; lack of technical experts (Huang \& Chi, 2013; Madrid-Guijarro et al., 2009; Tourigny \& Le, 2004; Xie et al., 2010).

Information-related problems refer to the lack of information on technology and markets as well as dissemination of information (Arundel, 1997; Baldwin \& Lin, 2002; Galia \& Legros, 2004; Larsson, 2004; Mohnen \& Roller, 2005; Vrgovic et al., 2012). Information-related barriers to SMEs in papers concern the lack of technical information (Xie et al., 2010).

In literature we can find barriers related to the market. Some papers consider supply of innovations and market conditions (Baldwin \& Lin, 2002; Mohnen \& Roller, 2005; OECD, 2005). Others mention 
lack of customer responsiveness to new goods or services (Galia \& Legros, 2004; Larsson, 2004). The third part of papers concerns lack of opportunities for cooperation with other firms and technological institutions (Mohnen \& Roller, 2005). In papers we can find one more market-related obstacle to innovations from the competitors' side: innovation being too easy to copy (Hadjimanolis, 1999).

On the one hand innovative companies face a shortage of resources because of high costs of their activity (Baldwin \& Lin, 2002; Galia \& Legros, 2004; Larsson, 2004; Mohnen \& Roller, 2005; OECD, 2005; Vrgovic et al., 2012). On the other hand they are excessively sensitive to the economic risks (Galia \& Legros, 2004; Larsson, 2004; Madrid-Guijarro et al., 2009). As innovation activity is too costly and risky, companies which are going to start innovation activity can need some support. Such impediments as insufficient government support and lack of government assistance were marked in some papers (Hadjimanolis, 1999; Madrid-Guijarro et al., 2009). Support services are more demanded by SMEs that is why we separately submit the following obstacles: lack of technical support and weakness in the technology market; insufficient government support (Huang \& Chi, 2013; Madrid-Guijarro et al., 2009).In order to reduce risks and to support innovative companies we can see special infrastructure in the regions (from buildings to services) including technology support network. So, several scholars note the lack of regional infrastructure as a barrier to innovations (Scozzi et al.; Sharma et al., 2012; Zeleny, 2012).

It is necessary to note the institution-related problems. Besides they concern government bureaucracy, insufficient flexibility of regulations or standards, legislation, and taxation (Arundel, 1997; Baldwin \& Lin, 2002; Galia \& Legros, 2004; Hadjimanolis, 1999; Larsson, 2004; Mohnen \& Roller, 2005; OECD, 2005; Vrgovic et al., 2012).

\section{Russian context}

In Russia we can find some studies that analyze factors affecting innovation activity of Russian companies. Statistical annals identify indicators of innovation activity of Russian companies including the rating of factors hindering technological innovations in Russia. They study all types of Russian companies from such industries as extractive and IT. The results show that the most significant factors are typical for other countries, but there are some impediments that are different: shortage of the legislative norms for innovation activity, uncertainty of economic outputs from the intellectual property use, a low innovation potential of the company, and undeveloped innovation infrastructure (Gorodnikova et al., 2014). In some other research we can see the same significant factors, but authors stress the lack of legal norms that regulate and support innovation activity as another main barrier (Kazakova et al., 2009).

We cannot find any papers measuring impediments to innovations for small companies in Russia. However, hindering factors for small business in Russia are studied annually by the GEM team. The object of the research is entrepreneurship at different phases including new business and established business that belong to a small business category. In 2012 they identified several most important structural fac- tors that, from the experts' point of view, influence the small business in Russia: access to finance, implementations of the innovations, government programs, barriers to market entry, bureaucracy, education, and government policy. Additionally, they have determined factors affecting the small business most seriously exactly in 2012: government policy, social and economic situation, financial support, and education (Verkhovskaya et al., 2013).

In this paper we identified obstacles to small innovative businesses in the Russian regions with high innovative potential and great level of socio-economic indicators. Nizhny Novgorod region was chosen as typical case of such a region due to several reasons. Nizhny Novgorod region has high levels of social, economic and innovative development in the area. The region took the fourth place in the ranking of innovative development in 2012 (Gokhberg, 2014). In the ranking of innovative activity of regions, Nizhny Novgorod was at the fourth place (Silvernagel et al., 2009). This area has a lot of scientific institutions, universities and large companies representing different industries.

The Nizhny Novgorod region was studied previously. As a result of 30 interviews with small innovative companies the main issues faced by small innovative businesses were found out: lack of venture capital and grants for small innovative companies; investors' decisionmaking opacity; inefficient information exchange in the community; a number of issues related to technology transfer (Aleksandrovsky et al., 2011). However, the opinion of companies cannot ultimately reflect the real situation and it is important to study the opinions of experts and representatives of support infrastructure, which work closely with small innovative companies and understand the barriers from the other side. In that research we focused on the opinion of representatives of innovative infrastructure.

Federal Law on Science and State Science and Technology Policy (1996) gives a broad interpretation of the term innovative infrastructure and defines it as a set of organizations contributing to the implementation of innovative projects, including the provision of administrative, logistical, financial, information, HR-related, advisory and organizational services. Dezhina (Dezhina) divides elements of innovation infrastructure into five main types: financial, information, consulting and service, personnel, industrial and technological infrastructure.

It can be summarized that obstacles to small innovative companies have been widely studied in Russia and abroad and there is a number of typical barriers. Despite a great number of works devoted to the development of innovative business barriers at the regional level, there seems to be a gap in the study of the factors associated with the functioning of innovative support infrastructure.

So in our research we need to understand what kind of factors concerning the innovative and support infrastructure for small business exist in Russia, how they are different from foreign countries, but typical for regions with a high level of economic development and innovative activity on the whole. 
Therefore, the following research problem can be formulated as follows: regions with high scientific and innovation potential have their own particular external obstacles concerned collaboration among companies and innovative infrastructure.

\section{Methodology}

The choice of the Nizhny Novgorod region as the object of the research can be justified by its high level of socioeconomic and innovation development. It is a typical region with a high level of science and innovation potential, as well as economic development. It includes high concentration of scientific industrial companies and research facilities. In 2012 this region occupied the fourth place in the Russian Regions Innovation Ranking (Gokhberg, 2014). In 2012 the National Association of Innovation and Development of Information Technology also rated innovative activity of Russian regions where the Nizhny Novgorod region occupied the fourth place. In our days there are 39 scientific institutions, 21 design bureaus, 14 Universities and 16 industrial research and development centers(Saavedra, 2009) (Saavedra, 2009). Additionally, regional business-incubators, technoparks, financial institutions such as business-angels network and venture fund are existed in the region. So, as a result we can see a lot of technological companies that were established over the last several decades in this region. All these factors as usual show a high level of involvement of small business into the innovative processes. At the same time we can see a low level of innovative activity of small business in the region.

However, certain barriers exist to the development of small innovative companies in the region. Preliminary research findings show that Nizhny Novgorod region hosts a number of different organizations that support small innovative businesses and provide the necessary services in all major areas of innovative infrastructure. It is therefore essential to find the key issues in financing, marketing, manufacturing and etc., main barriers hindering small innovative companies' development at the regional level.

In spite of the existence of different organizations enhancing innovative infrastructure in the region, not all of them fulfill their functions and fully satisfy their customers.

The overall goal of the research was to identify the barriers to development of small innovative companies in the Nizhny Novgorod region and find unique obstacles for such regions.

The research is based on the findings from previous studies conducted by Gokhberg (2014), the OECD (2005), and the outcome of the empirical study specially designed for this research.

According to the aim of the research, it is a case study, where we used qualitative methods in order to understand the functioning of key organizations that support innovative companies. The most appropriate method for data collection for such type of research would be the semi-structured personal interview (Sekaran, 2003). The guide for the interview was designed according to the type-specific problems of infrastructure.

Having considered a number of works to identify the problems of development of small innovative companies in different regions, the range of barriers was determined. The areas described below were used as the basis for the current study and for the compilation of interview questions.

Intellectual property protection. In this section experts answered the question of whether it is difficult to protect intellectual property in the region. Certain constraints such as protection of intellectual property exist only in Russia because of the lack of the international commercialization strategy (Gutierrez \& Correa, 2012).

Financial support of small innovative companies. In this unit the experts estimated the level of availability of financial resources for small innovative companies, how easy it is to get a grant or to find a private investor. Among the barriers in financial infrastructure it is possible to identify the lack of proprietor funds of project developers, the limited public funding (Doloreux, 2004; Kazakova et al., 2009; MadridGuijarro et al., 2009; Savignac, 2006; Sharma et al., 2012; Silva et al., 2007; Vermeulen, 2005; Xie et al., 2010), a small number of venture capitalists (Sharma et al., 2012), the high cost of new product development (Doloreux, 2004; Silva et al., 2007; Tourigny \& Le, 2004).

Information support and availability. In the information section it was important to get answers to questions such as how the leaders of innovative projects are aware of the possibilities of state support for innovation, and about the organizations that provide services and support to innovative companies and projects, whether it is difficult to find the necessary information for the project in free access. Constraints of the information infrastructure included: the lack of information and support from the state (Doloreux, 2004; Madrid-Guijarro et al., 2009; Silva et al., 2007; Xie et al., 2010).

Consulting support in the region. The questions in this section were to find out whether small innovative companies appeal to third party services, what services they want to get access to. Barriers from consulting, and business service infrastructure, according to the foreign researchers, are the lack of opportunities for cooperation with other enterprises (Doloreux, 2004; Madrid-Guijarro et al., 2009; Tourigny \& Le, 2004).

Education sphere and personnel. In this block the experts were asked to evaluate the level of competence of the team of innovative projects, what kind of competences they lack, if they have problems with finding, attracting and retaining qualified staff. Among barriers in the sphere of education can be named the insufficient amount of special educational programs in the field of entrepreneurship and small innovative business development, low qualification of the personnel (Madrid-Guijarro et al., 2009; Tourigny \& Le, 2004), low and, consequently, uncompetitive average earnings for researchers in the global market (Gutierrez \& Correa, 2012), low quality of education, 
poor understanding of customer needs, the lack of knowledge on the development and commercialization of project management skills, skilled labor deficit (Doloreux, 2004; Kazakova et al., 2009; Sharma et al., 2012; Silva et al., 2007; Vermeulen, 2005; Xie et al., 2010).

Other factors. It is important to ask firms about other problems that they face in the implementation of projects, so in this unit experts were interviewed on the legislation in the sphere of innovation, bureaucracy, about the economic risks of innovation. Barriers from the organizational and production infrastructure include the difficulty of getting access to university laboratories (Doloreux, 2004). Corruption, bureaucracy and legislative weaknesses are also constraints for Regional Development (Kazakova et al., 2009; Sivak et al., 2011; Vermeulen, 2005) and high economic risks (Silva et al., 2007; Tourigny \& Le, 2004).

Results of a similar study gave additional information about the situation in the region. Previous research was conducted in Nizhny Novgorod region in 2011, and management of small innovative companies was interviewed. The authors examined the following issues: protection and use of intellectual property, finance, interaction with suppliers, information support, and collaboration with other participants of the innovative infrastructure (Aleksandrovsky et al., 2011). To meet the aim of the research it is necessary to cover additionally representatives of the innovation infrastructure of the Nizhny Novgorod region.

In order to find referent experts for the interview, first of all we analyzed the database of organizations of innovation infrastructure in the Nizhny Novgorod region that was provided by the Ministry of Industry and Innovation of Nizhny Novgorod. According to the Ministry, the database consists of 36 organizations of innovative infrastructure in the Nizhny Novgorod region. Next, organizations from the base were divided into blocks in accordance with the type of support they provide, their aims and functions. Then the information on each was taken from secondary sources by its activity level in the region as a support organization in terms of innovation (participation in events for small innovative business, such as conferences, educational programs, fairs, business-plan competitions and so on; the flow of projects seeking the help from these organizations). Additional information about these organizations was received from the previous study, where the respondents were SMEs. In the end we selected the most active organizations from each group, so that we found out 19 representatives of innovative infrastructure.

To conduct interviews for this study the heads of the selected organizations were taken, because they own comprehensive information about the innovative development of the region.

Based on the selected type of infrastructure, interviews were held with following experts (more detailed information about experts is presented in the Appendix A):

- Financial infrastructure: representatives of grant programs, the Head of the Business Angels Association and the regional venture fund ( 3 respondents in this study);

- Industrial and technological infrastructure: representatives of business incubators, technology parks and the Innovation and Technology centre (4 experts);

- Information infrastructure: top management of the scientific information center; chief editor of a specialized journal, top-management of information resources for the actors of the innovative system ( 3 interviewees);

- Education and human resources infrastructure: managers of university programs teaching and training innovative managers and specialists in commercialization of innovations (4 respondents);

- Expert consulting infrastructure: leaders and experts from organizations supporting small innovative companies in the region (business incubators, centers for entrepreneurship, venture partner of RVC Seed Fund, consulting and intermediary organizations, innovation and technology centers) (5 experts).

The representatives of the target group gave the information about the Nizhny Novgorod case in the form of personal interviews. All interviewers used tape recorders and spent around 30 minutes on each personal interview. In total 19 interviews were conducted in 2013.

For the analysis of the interviews, each block of questions was considered separately. A number of barriers that each respondent identified was drawn up for each block of questions. As a result, the most popular barriers in each block of questions were identified.

\section{Results}

In this part of the article the results of the research are presented. They are grouped by the type of infrastructure: financial, information, consulting and business service, personnel, industrial and technological infrastructure.

As the result of the survey, the most important barriers to the small innovative companies' development in the region have been defined for each type of infrastructure (Table 1). 
Personnel infrastructure. The region has a shortage of qualified project managers, experts in the field of venture capital investment, skilled marketing experts and engineers.

Consulting infrastructure. Teams of small innovative companies usually involve technical staff, but have a gap of competencies in sales, management and marketing.

Financial infrastructure. The procedure for obtaining grants is complex and bureaucratized. There is a

shortage of venture capital for the seed stage.

Information infrastructure. The low level of awareness of small innovative companies and other partici-

pants in the innovation system about events and activities, procurement and types of support.

Industrial and technological infrastructure. Universities currently have only a technical base (special

laboratories, equipment and technical facilities), but do not seem to provide enough consulting, men-

toring and business services.
16

\section{3}

10

8

Table 1. Number of experts noted the most popular barriers in each type of infrastructure.

\section{Personnel infrastructure}

This set of issues describes the educational component of the infrastructure of the region and that of the innovative projects staff.

The table shows that 16 people out of 19 mentioned as the main barrier in the area of personnel the shortage of qualified project managers, experts in the field of venture capital investment, skilled marketing specialists and engineers in the region.

Vice President of innovation activity of the research university: "We can see that teams of the projects at the seed and pre seed stages consist only of technical experts and research managers. Teams, which include consultants and have an efficient structure (board of directors, people who is responsible for finance and for marketing) can be found very rarely. They do not conduct any market analysis, they do not know consumers and do not know how to design a financial model, how to attract consultants to the Board of Directors and competently protect intellectual property of the project."

Some experts indicate that the region lacks experts in the intellectual property management (patent attorneys, lawyers specializing in disputes related to intellectual property protection). Problems connected with the protection of intellectual property exist mainly in Russia. This is due to weak legislation in this area. However this obstacle is typical only for the Nizhny Novgorod region.

\section{Consulting infrastructure}

This block includes questions related to consulting and business service support of small innovative companies.

Small innovative companies' teams usually involve technical staff, but have a gap of competencies in sales, management and marketing. In this study 13 respondents mentioned this barrier as the most important one. According to the experts, they experience shortage of such services as: market research and promotion of the company; clients search; getting patents, permits and certification; legal support in the intellectual property management; business accounting services; finding and attracting grants and investments.

The Director of the Association of Business Angels: "Now more companies are turning to the services of third parties. At different seminars for small innovative companies we constantly call for collaboration with professionals, because without competent management and marketing it is impossible to bring the project to the market."

The barriers listed above are characteristics for many regions where small innovative companies are actively developing. In the investigations of Larson (2004), Mohnen and Roller (2005), Mancusi and Vezzulli (2010), Zeleny (2012) these issues in the field of consulting are of paramount importance.

However the study of each region can identify its unique challenges. For the Nizhny Novgorod area such barrier is the poor current service from business-incubators, innovation centers, universities and other organizations that cannot meet needs of small innovative companies. Market services of consulting agencies are too expensive for small businesses.

At the same time, universities do not seem to create favorable conditions for the development of innovative projects. Moreover, there is an unmet need for mentoring to package and support projects, and to hold negotiations with potential customers and investors. It is difficult to attract businessmen to be mentors and work with small innovative companies teams. The system of payment for their help is only to be created. 


\section{Financial infrastructure}

This group describes the availability of financial resources for small innovative companies. Most experts believe that for the project team it is difficult to attract both public and private capital for business development for a number of reasons.

The first problem mentioned was the lack of financing for high-tech projects at the seed stage. The procedure for obtaining grants is complex and bureaucratized. Venture capital for the seed stage is missing. These problems have been identified in studies of other authors, such as Larson (2004), Huang and Chi (2013), Aleksandrovsky, Butryumova and Nazarov (2013), Hadjimanolis (1999), Baldwin and Lin (2002), Mohnen and Roller (2005). In this study it is found that 10 out of 19 experts have noted these problems.

A representative of the business-angels network: "As small businesses often say one of the most serious and important issue is initial funding. They do not have their own money to finance the project."

The next deterrent regards private investors. The respondents indicated that private investors tend to fund less risky, fast payback and small investment projects. However, if the project has already attracted a grant, it will be much easier for the team to obtain investment from private investors. Hadjimanolis (1999), Mancusi and Vezzulli (2010) have also revealed such challenges in the studies of other regions.

These problems highlighted by many researchers are typical for any region in many countries all over the world. But the Nizhny Novgorod region has unique challenges peculiar only to this area. The first barrier is people's incompetence. Many of the projects that applied for the investment were not attractive for investors for several reasons: the majority of the teams do not have enough experienced and competent staff; many projects failed to undertake the previous study of the market and competitors; business model and financial model of the project were poorly designed. Presentation and negotiation skills are largely absent when communicating with potential investors. Besides, market services of consulting agencies are not available for small businesses because they lack money.

Representatives of the financial infrastructure noted a weak flow of innovation projects that applied for any support in the region.

\section{Information infrastructure}

This group describes the innovative projects teams' awareness of the opportunities of the government support for innovation in the region, activities carried out and the availability of various databases of intellectual property objects, events, participants of innovative market and etc.

In the table above we can see that 8 respondents pointed to the main problem in this block as the low level of awareness of small innovative companies and other participants in the innovation system of activities, procurement and types of support. The information about competitions, grants, tenders is either closed or not widely publicized. There are problems concerning the poor organization of the informa- tion resources in the Internet, a narrow focus, and the lack of sites collecting and presenting all the necessary information in one place. Such barriers encounter in many areas around the world, including the Nizhny Novgorod region, and such researchers as Baldwin and Lin (2002), Larson (2004), Mohnen and Roller (2005) identified these barriers in their studies.

The representative of a scientific research university: "Only the most advanced participants are aware of ongoing activities. This is a smaller part consisting of the business people who are always looking for opportunities how to reduce the financial burden that falls on their company at the expense of certain grants, subsidies and etc. People of science are usually not aware of the support programs."

The research participants indicated the obstacles that are specific only to this region. For instance, a low standard of organization of events dedicated to the development of innovative companies and projects. Organizers of such events often chose the inconvenient time and place, combine multiple activities in one place to decrease costs and attract more visitors (but not the target audience). It leads to the loss of interest in such events and, moreover, to the low level of collaboration among actors of the innovation system.

Another major problem indicated is a low interest in such events from the part of large businesses. Many respondents have noted that such activities should be funded by large business. However, it will happen only in case of the increase of demand for innovative products of small businesses in the region.

\section{Industrial and technological infrastructure}

The questions in this section relate to the functioning of technology parks, business-incubators, shared facilities centers, and innovative infrastructure in the universities.

The main obstacle in this sphere which is marked by 7 experts in the interview, according to the table above, is that universities currently have only a technical base (special laboratories, equipment and technical facilities), but do not seem to provide enough consulting, mentoring and business services.

The region also lacks incubators or specialized centers based in the universities (e.g., proof of concept centers), that would involve the academic community in the processes of technology transfer and would help to create and develop innovative projects.

The representative of the Venture Fund of the Nizhny Novgorod region: "Business incubators are a very effective mechanism to support companies of the Nizhny Novgorod region. Business incubators are developing in the universities now. However there is lack of innovative managers who could facilitate these processes. There is a shortage of competent people who are able to develop these processes. Basically, the whole businesses are built on human relations in the team."

Besides, according to the experts, there is a shortage of prototyping centers and centers of test batch manufacturing in the region as it is not 
profitable for large enterprises to produce small batches of products. Moreover, the existing industrial parks mostly focus on IT-industry and do not have specialized areas, equipped for production. These issues are typical for the regions where the development of innovative business has begun only recently, including many regions of Russia. Kazakova, Nasedkina, and Frantsuzova (2009), Huang and Chi (2013), Tourigny and Le (2004) also found such barriers in their studies.

As a result of this research some problems have been brought out, which are not presented in other regions. Several types of incubators and technology parks' services exist only on paper and are not provided in reality. Consulting support to the residents of incubators and technology parks is provided by the staff of these organizations, they do not have any means to pay for professional services from external experts.

The interviewees noted a weak influx of residents to the existing incubators and technology parks. The number of projects that meet their requirements is extremely small. It can be thus concluded that projects need to be accompanied and mentored already at the seed stage, before entering the incubators.

The problems mentioned during the interviews additionally include constraints that are related more to the functioning of the entire innovation system rather than to a specific type of innovation infrastructure.

The majority of such issues concern intellectual property protection and the process of technology transfer. Poor legislation for intellectual property protection and low penalties for companies that infringe intellectual property rights lead to a low demand for the services of lawyers and low incentives to undertake an innovation activity on the whole. The lack of demand for innovations from the industry on the one hand and innovation supply from the scientific community mismatches the industry need on the other hand. Weak motivation of scientists to commercialize their intellectual property is rooted in the high risk of such activity. It hinders the development of the intellectual property market.

The other issue named by the experts is the unfavorable business climate in the country, in particular, insufficient incentives and benefits for small innovative companies. Low trust among actors of innovation system leads to poor cooperation. Moreover, some features of the innovative infrastructure are either duplicated or missing, so the system obviously has operational deficiencies.

\section{Conclusions}

The study attempted to identify the problems and factors affecting the small innovative companies' development, which arise from the interaction between them and the innovation infrastructure of the Russian regions with a high innovative potential and high level of socio-economic indicators.

The barriers identified by large Russian companies and other experts (Gorodnikova et al., 2014; Kazakova et al., 2009; RVC, 2010) demon- strate the general problems for innovations in the Russian economy, but do not focus on the specific features of small business. The suggested research was aimed at confirming several impediments faced by both small and large companies, such as bureaucracy, underdeveloped legal framework, lack of finance, insufficient state support for innovation, low innovation potential of companies and lack of highskilled staff, lack of information about new technologies and markets, and weakness of cooperation links.

To recapitulate, the project is an attempt to enhance our understanding of problems in the innovation sphere in the region. The study revealed that in addition to the previously identified barriers, there may appear other restrictions to the innovation development, such as a bureaucratic process of reception and expenditure of the public funds allocated to the project; the low level of projects' elaboration; poor organization of the information resources; weak awareness of the participants of innovative system of the activities of each other and of the support programs; the weak system of providing innovative companies with available services of the third-party organizations; lack of specialists in intellectual property management.

The findings prove the systemic issues that were identified in the previous research of managers of small innovative companies undertaken in the Nizhny Novgorod region in 2011. However the present analysis has revealed some issues specific to small innovative companies in the region. The main differences in opinions were in the degree of projects preparedness and investor activity. According to the experts, the projects submitted to various funds were poorly designed and needed the packaging support to attract funding, whereas the project developers were mostly unable to do that themselves. In the opinion of the leaders of small innovative enterprises, investors were too critical about the projects, refused to invest in a risky business, required a major share of the company, and interfered in the operational management of the company. Additionally authors of the projects do not trust investors and they are afraid that the main know-how can leak out from the project. In contrast, support organizations assure them that they are ready to collaborate and deal with the authors honestly.

The result of the Nizhny Novgorod case study from a scientific point of view is a list of factors for further quantitative studies to determine the influence of the most important factors on the activity and development of small innovative companies. Particularly noteworthy are such obstacles as the management and protection of intellectual property, and legislative barriers to innovations.

The findings of the research could assist policy-makers in meeting the needs of small innovative companies and adjusting support programs. Small innovative companies are a driver for economic growth and it is an acute question for many regions how to support and develop this phenomenon. Therefore, it is necessary to eliminate the obstacles to small innovative companies' development. The practical significance of this research for the government is in improvement of the situation in the region by implementing recommendations according to the infrastructure type. 
Financial infrastructure. The government should facilitate the procedure of obtaining government grants for innovative projects. It's significant to create a seed fund and develop a system to its full operation and interaction with existing innovative infrastructure elements of the Nizhny Novgorod region. The government must co-finance innovative projects together with private investors to reduce the risk for each part.

Information infrastructure. It is important to announce ongoing activities in different mass media (advertising on billboards, in business magazines, on the Internet website of the Ministry of supporting small business and the Ministry of industry and innovation, as well as online resources of other innovation infrastructure organizations, putting up posters in universities and business centers). It is necessary to involve large business in such projects as conferences, competitions, summits and other events for small innovative business development.

Personnel infrastructure. It is significant for the region to develop and implement new educational programs in higher education institutions for the training of specialists in the field of venture management, marketing, project management, intellectual property protection. Also, it is advisable to carry out joint activities for teams of small innovative enterprises and students from such programs as venture management, innovation management and marketing.

Industrial and technological infrastructure. The state should create Joint Use Centers and prototyping centers for manufacturing production test batch. It is important to develop technology transfer centers at universities that would really work and help project goes not only to the Russian market, but also abroad.

Results of the Nizhny Novgorod case study may help other countries to predict the same issues and adapt their policies to possible impediments that their innovative companies may face. Moreover, researchers from other countries can use the results of this research as hypotheses for their study. They don't need to look for what barriers there are in the region, and their purpose is to verify the presence of such obstacles in the studied region.

For the regional government it should be recommended to improve support programs in such aspects as collaboration among participants of innovative infrastructure, launching of the seed financial mechanisms, more educational programs for managers of innovative projects, better provision of access to the information resources, mentorship support programs, and special support for manufacturers.

\section{Acknowledgements}

This study was carried out within The National Research University Higher School of Economics Fund Program in 2013 (Faculty of Management - Nizhny Novgorod).

Contribution of authors. Nadezhda Butryumova is a head of the research project; she developed a design of the study, coordinated the data collection and the data analysis, and wrote the manuscript.
Svetlana Karpycheva carried out a literature review, participated in data collection and analysis, and helped draft the manuscript. Elena Kasyanova participated in data collection and analysis, helped draft the manuscript. Khristina Grisheva participated in data collection and analysis, helped draft the manuscript.

\section{References}

\section{Uncategorized References}

Aleksandrovsky, S., Butryumova, N., \& Nazarov, M. (2011). Barriers to the development of innovative entrepreneurship in the Nizhny Novgorod region. Financial analytics: problems and solutions, 46, 21-33.

Arundel, A. (1997). Enterprise strategies and barriers to innovation. Innovation Measurement and Policies, 50, 101-108.

Baldwin, J., \& Lin, Z. (2002). Impediments to advanced technology adoption for Canadian manufacturers. Research Policy, 31, 1-18.

Dezhina, I. (2005). Does Russia need a small high technology business? . People and work, 3(3), 53-59.

Doloreux, D. (2004). Regional Innovation Systems in Canada: A Comparative Study. Regional Studies, 38(5), 479-492. doi: $10.1080 / 0143116042000229267$

Galia, F., \& Legros, D. (2004). Complementarities between obstacles to innovation: evidence from France. Research Policy, 33(8), 11851199. doi: 10.1016/j.respol.2004.06.004

Geroski, P. (1995). Innovation and Competitive Advantage. OECD Economics Department Working Papers, No. 159. doi: $10.1787 / 344434438114$

The Global Innovation Index 2013. The Local Dynamics of Innovation. (2013). In S. Dutta \& B. Lanvin (Eds.): Cornell University, INSEAD, the World Intellectual Property Organization.

Gokhberg, L. (Ed.). (2014). The rating of innovation development of the Russian Federation regions (2 ed.). Moscow: National Research University - Higher School of Economics

Gorodnikova, N., Gokhberg, L., Kuznetsova, I., Martynova, S., Popova, E., Ratay, T., . . Fridlyanova, S. (2014). Indicators of innovation activities: 2014: statistical yearbook (L. Gokhberg, Y. Kuzminov, K. LAYKAM \& O. Fomichev Eds.). Moscow: National Research University Higher School of Economics.

Gutierrez, J. J., \& Correa, P. (2012). Commercialization of Publicly Funded Research and Development (R\&D) in Russia. Scaling up the Emergence of Spinoff Companies Policy Research Working Paper: The World Bank.

Hadjimanolis, A. (1999). Barriers to innovation for SMEs in a small less developed country (Cyprus). Technovation, 19 561-570. 
Huang, X., \& Chi, R. (2013). Innovation in China's high-tech industries: barriers and their impact on innovation performance. International Journal of Technology Management, 62(1), 35-55.

Kazakova, N. A., Nasedkina, T. I., \& Frantsuzova, I. I. (2009). Analysis of factors in the formation of innovative models for regional economic development: Russian and international experience. . Management in Russia and abroad, 3, 56-61.

Larsson, A. (2004). Innovation output and barriers to innovation. Statistics in focus: SCIENCE AND TECHNOLOGY, (KS-NS-04-001EN-N, THEME 9).

Madrid-Guijarro, A., Garcia, D., \& Van Auken, H. (2009). Barriers to Innovation among Spanish Manufacturing SMEs. Journal of Small Business Management, 47(4), 465-488.

Mancusi, M. L., \& Vezzulli, A. (2010). RઐD, Innovation, and Liquidity Constraints. Paper presented at the 2 nd Conference on corporate R\&D (CONCORD - 2010). CORPORATE R\&D: AN ENGINE FOR GROWTH, A CHALLENGE FOR EUROPEAN POLICY, Bocconi University, Milano.

Mohnen, P., \& Roller, L.-H. (2005). Complementarities in innovation policy. European Economic Review, 49, 1431-1450.

OECD. (2005). Oslo Manual. The measurment of scientific and technological activities proposed guidelines for collectiong and interpreting technology innovation data.

OECD. (2013). OECD Regions at a Glance 2013

OECD Publishing.

Piatier, A. (1984). Barriers to Innovation: A study carried out for the Commission of the European Communities, Directorate-General Information Market and Innovation: Frances Pinter (Publishers) Ltd.

Ramos-Vielba, I., \& Fernández-Esquinas, M. (2012). Beneath the tip of the iceberg: exploring the multiple forms of university-industry linkages. Higher Education, 64(2), 237-265. doi: 10.1007/s10734-011-9491-2

RVC. (2010). Innovation by Large Companies in Russia: Mechanisms, Barriers, Perspectives (pp. 40). Moscow: Russian Venture Company.

Saavedra, M. (2009). Problemática y desafíos actuales de la vinculación universidad empresa: El caso mexicano. Actualidad contable FACES, 12(19), 100-119.

Savignac, F. (2006). The impact of financial constraints on innovation: evidence from French manufacturing firms. In C. d. E. d. l. Sorbonne (Ed.), Cahiers de la Maison des Sciences Economiques (pp. 42). Université Paris1 Panthéon-Sorbonne.
Scozzi, B., Garavelli, C., \& Crowston, K. (2005). Methods for modeling and supporting innovation processes in SMEs. European Journal of Innovation Management, 8(1), 120-137. doi: $10.1108 / 14601060510578619$

Sekaran, U. (2003). Research Methods for Business: a Skill Building Approach (4th Edition ed.). New York: John Wiley \& Sons, Inc.

Sharma, P., Nookala, S. B. S., \& Sharma, A. (2012). India's National and Regional Innovation Systems: Challenges, Opportunities and Recommendations for Policy Makers. Industry \& Innovation, 19(6), 517-537. doi: 10.1080/13662716.2012.718878

Silva, M., Leitao, J., \& Raposo, M. (2007). Barriers to Innovation faced by Manufacturing Firms in Portugal: How to overcome it? : Munich Personal RePEc Archive.

Silvernagel, C., Schultz, R. R., \& Moser, S. B. (2009). Student-generated intellectual property: perceptions of ownership by faculty and students. Journal of Entrepreneurship Education, 12, 13-33.

Sivak, R., Caplanova, A., \& Hudson, J. (2011). The impact of governance and infrastructure on innovation. Post-Communist Economies, 23(02), 203-217. doi: 10.1080/14631377.2011.570050

Tourigny, D., \& Le, C. D. (2004). Impediments to innovation faced by Canadian manufacturing firms. Economics of Innovation and New Technology, 13(3), 217-250. doi: 10.1080/10438590410001628387

Verkhovskaya, O. R., Dorokhina, M. V., \& Sergeeva, A. V. (2013). National Report. Global Entrepreneurship monitor. Russia 2013. St. Petersburg: Graduate School of Management, St. Petersburg University.

Vermeulen, P. A. M. (2005). Uncovering Barriers to Complex Incremental Product Innovation in Small and Medium-Sized Financial Services Firms. Journal of Small Business Management, 43(4), 432-452.

Vrgovic, P., Vidicki, P., Glassman, B., \& Walton, A. (2012). Open innovation for SMEs in developing countries - An intermediated communication network model for collaboration beyond obstacles. Innovation: Management, Policy and practice, 14(3), 290-302.

Weigand, J., \& Audretsch, D. B. (1999). Does Science Make a Difference? Investment, Finance and Corporate Governance in German Industries. CEPR Discussion papers, (2056). London.

Xie, X. M., Zeng, S. X., \& Tam, C. M. (2010). Overcoming barriers to innovation in SMEs in China: A perspective based cooperation network. nnovation: Management, Policy and practice, 12(3), 298-310.

Zeleny, M. (2012). High Technology and Barriers to Innovation: From Globalization to Relocalization. International Journal of Information Technology \& Decision Making, 11(02), 441-456. doi: 10.1142/ s021962201240010x 


\section{Appendix A}

\section{List of respondents}

1. NP "Business Angels Association" Start Invest", Director.

2. Administration of the Nizhny Novgorod Region, Deputy Governor, Deputy Prime Minister of the Nizhny Novgorod region.

3. Nizhny Novgorod Venture Fund, Deputy Director.

4. Innovation and Technology Centre, Lobachevsky State University of Nizhny Novgorod - National Research University, Director.

5. The Institute of Applied Physics of the Russian Academy of Sciences (IAP RAS), Head of innovative program department.

6. Innovation Business Incubator of the Nizhny Novgorod Region, Deputy Director.

7. SarovTechnopark, Head of Investment Department.

8. Nizhny Novgorod Scientific Information Center, Director.

9. Nizhny Novgorod Scientific Information Center, Deputy Director.

10. The Angel Investor Journal, Chief Editor and Publisher.
11. National Research University Higher School of Economics, City of Nizhny Novgorod, Dean of the Advanced Training Department.

12. Lobachevsky State University of Nizhny Novgorod - National Research University, Head of International Business Program EURECA.

13. Youth business community "Koleso", Executive.

14. The Ministry of Education of the Nizhny Novgorod Region, Deputy Minister.

15. Venture Company “Start Investment", Director

16. Nizhny Novgorod State Technical University n.a. R.E. Alekseev (NSTU), Associate Professor.

17. National Research University Higher School of Economics, City of Nizhny Novgorod, Deputy Head of the Center for Entrepreneurship.

18. Marchmont Capital Partners, Founder. Lobachevsky State University of Nizhny Novgorod - National Research University, Vice-rector for Innovations.

19. Business Angels Association "Start Investment", President. National Research University Higher School of Economics, City of Nizhny Novgorod, Head of Venture Management Department. 